\title{
STANLEY CAVELL Y EL DEBATE SOBRE LA “NUEVA MÚSICA": RAZONES Y SINRAZONES DE UN DESENCUENTRO
}

\author{
David Díaz Soto \\ Universidad de La Rioja
}

\begin{abstract}
RESUMEN: Examinaremos las críticas dirigidas por el filósofo Stanley Cavell (hoy más conocido como teórico del cine), en algunos de sus textos tempranos, contra ciertas prácticas de la vanguardia musical de los años 60. Situaremos dichas críticas en el contexto de la teoría cavelliana de la modernidad, del acto creativo y de los "medios" artísticos, de la cual se sigue una peculiar concepción "dramática" del medio musical. Cavell dice suscribir una posición "modernista" en relación con el arte reciente, inspirándose en Clement Greenberg, el gran teórico del modernismo tardío; no obstante, señalaremos aspectos importantes en los que la posición de Cavell discrepa de la de un formalista como era Greenberg. Pondremos así de relieve el carácter "eticista" de la posición de Cavell en materia de estética y teoría del arte; entendiendo por "eticismo" aquella posición que, sin necesariamente renunciar por ello a la tesis de la autonomía del arte, sostiene la relevancia de consideraciones éticas y morales en el juicio sobre fenómenos y prácticas artísticas. Terminaremos valorando la vigencia actual del discurso de Cavell sobre música.
\end{abstract}

Palabras clave: Música contemporánea, serialismo, música aleatoria, modernismo, autenticidad, fraudulencia.

\section{STANLEY CAVELL AND THE "NEW MUSIC" DEBATE: REASONS AND MISCONCEPTIONS OF THE DISAGREEMENT}

ABSTRACT: We will examine the objections addressed by philosopher Stanley Cavell (nowadays better known as a Film theorist) in some of his early writings to the musical avant-garde of the 1960's. We will contextualize these objections on the background of Cavell's theories about Modernism, the act of artistic creation, and the media of art; a corollary of these theories is Cavell's peculiar 
"dramatic" theory of music. Cavell admittedly espouses a "modernist" stance towards recent art, whose source of inspiration is noted High-Modernism theorist Clement Greenberg - although we shall show some important points in which Cavell disagrees with Greenberg's "formalist" position. Thus, we will point out to Cavell's "ethicist" approach, since he stresses the relevance of moral and ethical issues to the judgement on artistic issues and practices; although this does not necessarily imply giving up the notion of artistic autonomy. Finally, we will assess the present relevance of Cavell's ideas on music.

Keywords: Avant-garde classical music, serialism, aleatory music, modernism, authenticity, fraudulence.

Stanley Cavell viene atrayendo una creciente atención en el medio académico de nuestro país como pionero de las Ilamadas "filosofías post-analíticas", que combina de un modo personal ideas de su maestro John L. Austin con otras cercanas a Thomas S. Kuhn, proponiendo una muy personal lectura del Wittgenstein de las Investigaciones Filosóficas, pero también de los escritores del "trascendentalismo" norteamericano (Thoreau, Emerson, Whitman); ya sea para desarrollar penetrantes reflexiones sobre el destino escéptico del pensamiento moderno después de Descartes, o complejas interpretaciones, con un agudo filo ético, de grandes clásicos del cine narrativo. Son estos aspectos de su producción intelectual los que han centrado el interés de los intérpretes y estudiosos de este autor. Sin embargo, inicialmente Cavell recibió una formación académica principalmente musical, y tuvo la ambición de llegar a ser compositor, a la que luego renunció.

Aquí nos ocuparemos de aspectos del pensamiento de Cavell relacionados con su temprano interés por la música, pero que tuvieron escasa continuidad en su obra posterior, por lo que quizá han sido menos comentados ${ }^{1}$. Examinaremos las objeciones que en presenta Cavell en algunos de sus primeros textos, escritos a mediados de los años 60, a algunas de las corrientes importantes de la vanguardia musical de la época: principalmente, el serialismo integral y la música que emplea técnicas aleatorias ${ }^{2}$. Situaremos esas objeciones en el contexto de los

1. Las incursiones de Cavell en la estética musical han atraído poca atención, tanto en el medio académico español como en el anglosajón. Una importante excepción es el número monográfico, titulado Cavell's 'Music discomposed' at 40, del Journal of Music Theory, Vol. 54, no 1 (2010), pp. 75-90. La contribución a ese volumen más relevante en relación con nuestro propósito es la de Cox, F., "Stanley Cavell on modern music: 'Music discomposed' and 'A matter of meaning it' after forty years", pp. 37-60.

2. Varios de los primeros textos publicados por el autor, entre 1958 y 1969 , se recogen en Cavell, S., Must we mean what we say?, Cambridge: Cambridge University Press, 1976 (en adelante, MWM). También son relevantes: Cavell, S., The World Viewed: Reflections on the 
aspectos más relevantes de la teoría del arte propuesta tempranamente por Cavell (en particular, su concepción de la modernidad cultural, del acto creativo y de los "medios" artísticos). Dicha teoría en parte se inspira en el planteamiento formalista de Clement Greenberg (que fue uno de los grandes teóricos del "modernismo" artístico tardío). No obstante, como veremos, el planteamiento "modernista" de Cavell presenta importantes discrepancias respecto de Greenberg y del formalismo; pues Cavell adopta una posición de corte humanista, cercana al existencialismo, y plantea una concepción eticista de la esfera de lo estético. De ella se desprende la peculiar concepción "dramática" que Cavell tiene del medio específico del arte musical, así como muchas de sus objeciones contra la música de vanguardia de los años 60. Esto nos Ilevará a hacer algunas reflexiones finales sobre el alcance y la vigencia del discurso cavelliano sobre el arte musical.

\section{1. "Modernismo" y modernidad artística}

Cavell dice sostener una posición "modernista" respecto del arte y la cultura contemporáneos, y presenta su propio pensamiento como una propuesta de "modernismo filosófico". "Modernismo", término ligado a "modernidad", posee gran amplitud de connotaciones. En los países de habla inglesa se ha Ilamado "modernismo" (modernism), tanto al "movimiento moderno" de las vanguardias artísticas desde la segunda mitad del siglo XIX, como a las posiciones teóricas de abierto apoyo y militancia en favor del arte moderno (aunque, obviamente, hay mas de un modo de plantear esa militancia y de ser "modernista") ${ }^{3}$. En su juventud, Cavell se interesó por los poetas británicos y norteamericanos denominados "modernistas". También se interesó por las teorías que elaboraron, en estrecha conexión con la obra de aquellos poetas, algunos de los new critics, como F. R. Leavis o William Empson; si bien Cavell se opondría claramente a los teóricos del sector más "formalista" dentro de los new critics (como Monroe Beardsley y William K. Wimsatt, Jr., cuyos argumentos contra las falacias "intencional" y "afectiva" Cavell rechaza).

Y es que Cavell tiene una concepción muy personal del "modernismo" ${ }^{4}$, que toma como punto de partida las ideas del gran crítico de arte norteamericano y

Ontology of Film, $2^{\mathrm{a}}$ ed. ampliada, Cambridge, Mass.: Harvard University Press, 1979 (en adelante, TWV); y Cavell, S., The claim of reason, Oxford: Oxford University Press, 1979 (trad. cast. Reivindicaciones de la razón: Wittgenstein, escepticismo, moralidad y tragedia, trad. Diego Ribes, Madrid: Síntesis, 2003; citamos por el original inglés, en adelante, TCR), versión ampliada de la tesis doctoral de Cavell.

3. Este uso del término "modernismo" difiere de su empleo, aún hoy predominante en el ámbito de habla hispana, para designar al estilo artístico conocido también como Art Nouveau.

4. La caracterización del "modernismo" que propone Cavell está ligada a su teoría general sobre la modernidad, centrada en un tema clave de la filosofía cavelliana, que es el problema del escepticismo post-cartesiano, entendido como crisis de la relación inmediata y 
teórico del modernismo tardío, Clement Greenberg (en su primera época marxista, la de "Avant Garde and Kitsch"5), así como la teoría de las revoluciones científicas de Thomas S. Kuhn (sobre todo, su noción de "ciencia revolucionaria" $^{6}$. Cavell caracteriza la modernidad como época de la "situación modernista": una crisis permanente de las instituciones, valores y modos de vivir tradicionales, y de las "convicciones" profundas (otra noción central en Cavell, ligada al tema wittgeinsteiniano de los "modos de vida") que los habían venido sustentando. Para el arte, esto conllevaría una quiebra de todos los supuestos implícitos que hasta entonces lo fundaban como institución y lo regían como práctica de producción cultural, y que hacían posible reconocer algo como una obra de arte, o lo que para Cavell es lo mismo, como obra de alguna de las artes: "[ya] no está claro a priori qué cuenta, o contará, como pintura o escultura o composición musical...., así que no tenemos criterios claros para determinar si un objeto dado es o no una pintura, una escultura...."

A raíz de esa crisis, la actividad artística asumiría una difícil tarea, que tiene dos facetas complementarias. La primera es la sistemática puesta a prueba de dichas convenciones, de los recursos y límites que en cada momento se presuponen constitutivos de las distintas artes o prácticas artísticas, cobrando así cada una de éstas conciencia cada vez más aguda de sí misma y de sus propios supuestos $^{8}$. La obra de arte modernista obliga al espectador a constatar y revisar a cada momento sus propios presupuestos sobre qué es aquello que la constituye como producto de una determinada disciplina artística (y por tanto, como "obra de arte" a secas), y que la hace convincente como tal. "Ese descubrimiento es innecesario mientras hay una tradición" ${ }^{\prime \prime}$, puntualiza Cavell; porque, mientras la tradición aún no estaba en crisis, ella proporcionaba los criterios, y no se tomaba conciencia reflexivamente de ellos, sino que simplemente se creía y vivía en ellos.

Pero para Cavell esa crítica sistemática no implica una ruptura radical con la tradición, aunque pueda parecerlo; ya que la segunda faceta crucial de la tarea del arte moderno es que sus obras deben suscitar "convicción" de su valía como arte. En esto consiste el serio compromiso del arte modernista con la tradición.

confiada que, en la época premoderna, ligaba al sujeto con su mundo vital y los modos de vida tradicionales; crisis que daría lugar a una "pérdida del mundo" y a una duda insuperable del individuo sobre la humanidad de sus semejantes. Para esta cuestión, además de los textos de Must we mean what we say? (especialmente, MWM, pp. 322-324, 348), es de máxima relevancia Cavell, S., "Between acknowledgement and avoidance", la sección final de The claim of reason (amén de otros capítulos de esta misma obra).

5. Greenberg, Clement, "Avant Garde and Kitsch", en The Collected Essays and Criticism, ed. John O'Brian, Chicago y Londres: University of Chicago Press, 1986-1993, vol. I, pp. 5-22.

6. El propio Cavell señala su intercambio de ideas con Kuhn, de quien fue colega en la Universidad de Berkeley a fines de la década de 1950; cfr. MWM, pp. xii.

7. MWM, p. 219.

8. MWM, pp. 180, 186. 
Según Cavell, la existencia de una tradición (y no así una supuesta "esencia" atemporal y abstracta de lo artístico-en-sí) constituye el único sustrato que mantiene la identidad de las artes a través de los cambios, a veces muy profundos, que han experimentado a lo largo de la historia; y es ese sustrato lo que propiamente vincula las distintas artes en una unidad a la que llamamos "Arte". Esa tradición es un conjunto de riqueza cultural, dotada de valores. Por ello, y contra toda pretensión o apariencia de ruptura radical, lo que implica la situación modernista de crisis cultural de la tradición es que el único modo que tiene la creación artística actual de contribuir a la tradición, inscribirse en ésta y seguir enriqueciendo sus valores, es precisamente a través de la crítica sistemática de los presupuestos y convenciones vigentes relativas al arte: es sólo mediante dicha crítica como el arte moderno puede y debe lograr suscitar "convicción"; y el propósito de dicha crítica es contribuir a enriquecer la tradición artística, y no destruirla.

Cabe el riesgo de incurrir en un grave equívoco: el de pensar que realizar esa crítica consiste en hacer tabula rasa y situarse totalmente al margen de la tradición, en propugnar el final o la negación absoluta y abstracta del arte, haciendo de dicha negación el único propósito y contenido de la obra artística, sin preocuparse por suscitar convicción. De modo que sería también un rasgo constitutivo de la experiencia de la modernidad artística una permanente "amenaza de fraudulencia"10:

...la posibilidad de fraudulencia, y la experiencia de fraudulencia, es endémica en la experiencia de la música contemporánea; [...] su pleno impacto, incluso su relevancia inmediata, depende de una disposición a confiar en el objeto, sabiendo que el tiempo gastado en él, con todas sus dificultades, puede resultar traicionado. No veo cómo cualquiera que haya experimentado el arte moderno puede haber evitado experiencias tales, y no solo en el caso de la música ${ }^{11}$.

En una época de crisis de todos los criterios y convicciones tradicionales sobre qué son el arte y las distintas prácticas artísticas, y sobre qué es lo artísticamente valioso y legítimo, toda producción artística nueva está siempre bajo la sospecha de no ser legítimamente "artística", de ser sólo una artimaña espuria, presentada ante la audiencia para hacer pasar cualquier cosa por "arte" y lograr que sea valorada como tal.

9. MWM, pp. 219-220.

10. Sobre la experiencia de fraudulencia, cfr. Cavell, "Music Discomposed", MWM, pp. 188-189, 205, 211; "A matter of meaning it", MWM, pp. 214-215, 216, 220, 224; así como "Kierkegaard's On authority and revelation", MWM, p. 176.

11. MWM, p. 188. 
Como bien señala Franklin Cox, en el modernismo de Cavell, como en el de Greenberg, es crucial la distinción "alta cultura/baja cultura"12: el arte modernista es verdadero arte porque sólo él es "gran arte", como el de la tradición; y lo que no alcance ese nivel será "baja cultura", falso arte. Cavell sostiene la tesis (que Greenberg no llegó a afirmar) de que "arte" es un término en sí mismo valorativo, que implica una valoración positiva ${ }^{13}$. Por tanto, la distinción entre lo valioso y lo no válido en el arte moderno es radical, polar. Mientras la tradición estaba vigente, todo cuanto parecía valer como arte era, de hecho, realmente válido; y por ello, la discriminación en el juicio de las obras se refería a su mayor o menor grado de calidad. En cambio, de la obra modernista lo que se enjuicia es su "seriedad" (legitimidad); y de ella nunca cabe tener plena certeza: hay que reevaluarla a cada momento. La obra de arte moderna menor o fallida no es meramente "mala": peor aún, simplemente carece de "seriedad"; ni siquiera puede ser aceptada como obra artística genuina, y el término valorativo para calificarla será el de "fraudulenta". Resulta obvia la fraudulencia de aquellas obras carentes de toda reflexividad y filo crítico, que se limitan a cumplir al pie de la letra las convenciones artísticas vigentes, complaciendo servilmente las expectativas del espectador: se tratará de mera decoración, productos de consumo que tratan de hacerse pasar por "arte". Pero también puede haber fraudulencia en una obra de apariencia radicalmente crítica, cuando esa apariencia no responda a un compromiso "serio" con la tarea del arte moderno, con la situación de crisis de la tradición. Y en estos casos el asunto se torna más problemático.

De este modo, y a pesar de su militancia "modernista", Cavell se alinea junto a Clement Greenberg (fuente de inspiración para Cavell también en esto), quien desde mediados de los años 60 se implicó en una diatriba contra las corrientes artísticas de "neovanguardia", motivada por el empleo, gratuito en opinión de Greenberg, que dichas corrientes hacían de procedimientos artísticos mixtos y de nueva creación, y por las radicales pretensiones rupturistas de sus principales teóricos ${ }^{14}$. En esta polémica, también secundaron a Greenberg otros críticos, como Michael Fried (quien, sin embargo, se alejó rápidamente de la posición de Greenberg, para convertirse en un importante interlocutor de Cavell), así como

12. Cox, F., "Cavell on modern music", p. 46. Esta distinción era también el eje central del clásico ensayo "Avant Garde and kitsch" de Greenberg, y de la teoría del "modernismo" de éste.

13. Esta tesis cavelliana fue atacada por Monroe Beardsley, quien insistió en que "arte" es un término puramente descriptivo, en la sesión de debate en que Cavell presentó "Music discomposed" (recogida en: Captain, W. H. y D. D. Merrill (eds.), Art, mind and religion, Pittsburgh: University of Pittsburgh Press, 1967).

14. Ofrecemos un resumen de la posición teórica de Greenberg durante la "etapa intermedia" (la más formalista, y ya muy alejada de su marxismo inicial) de su producción teórica y crítica, desde fines de los años 50, en: Díaz Soto, D., "Modernismo, Forma, Emoción y Valor Artístico: Claves de la Teoría de la Modernidad Artística de Clement Greenberg", Bajo Palabra, 2ª época, no 2 (2007), pp. 159-166. 
varios seguidores de Greenberg de menor importancia; desde entonces, éstos serían considerados culturalmente conservadores, y dicha acusación quedaría ligada a la posición formalista, a la cual se los vinculaba ${ }^{15}$. Pero en esa discusión, Greenberg partía de supuestos procedentes de la teoría formalista del arte, tales como el vínculo de los distintos medios artísticos con distintas "esferas sensoriales" específicas. Supuestos con los que no se compromete Cavell, quien para discernir lo auténtico de lo fraudulento no cuenta con ningún criterio "sensorialista" de ese tipo, sino más bien con un siempre difícil juicio sobre la autenticidad y seriedad del compromiso del artista y de su obra con la propia tradición cultural a la que critican. Lo cual, como veremos, introduce en la posición de Cavell un elemento personalista, existencialista y romántico, bastante ajeno a la versión "formalista" del modernismo propuesta por Greenberg ${ }^{16}$.

\section{Una ética del acto creativo}

Tal como Cavell lo describe en sus textos "Music discomposed", "A matter of meaning it" $y$ "The avoidance of love", el acto creativo y su producto, la obra artística, puesto que surgen de una toma de decisiones consciente y deliberada por parte del artista ${ }^{17}$, tienen carácter eminentemente intencional. La obra artística es un tipo peculiar de objeto, que por parte del artista manifiesta la intención de "decir" algo, y expresa su "voz personal". Un objeto que "significa algo" para los espectadores, y que suscita en éstos, como sujetos, como personas, una respuesta individual de tipo emocional ${ }^{18}$, y una peculiar actitud hacia él, en virtud de la cual entablan con la obra de arte una relación de carácter interpersonal:

...los objetos de arte no nos interesan y absorben meramente; no nos implicamos meramente en ellos, sino que nos importan; los tratamos de maneras especiales, los investimos de un valor que, en general, la gente

15. A examinar la teoría del arte de Michael Fried en el contexto del este debate en torno al formalismo, que se ha venido desarrollando desde hace treinta años, hemos dedicado nuestra tesis doctoral: Díaz Soto, D., Michael Fried y el debate sobre el formalismo norteamericano, Madrid: Editorial de la UCM, 2009.

16. La posición de Cavell, pues, guarda una relación antagónica con el formalismo; es un error pensar que Cavell propugne un enfoque "formalista" en materia de estética y crítica artística (como se afirma en Bauer, A., "Cavell and the critique of New Music", en Cavell's "Music discomposed", p. 76). Las alusiones de Cavell en sus textos tempranos al formalismo estaban motivadas por ciertas afirmaciones de su joven amigo Michael Fried, que luego el propio Fried revocaría; cfr. Fried, M., Art and objecthood: Essays and reviews, Chicago and London: University of Chicago Press, 1998 , pp. 16-19 (trad. cast.: Arte y objetualidad: Ensayos y reseñas, trad. Rafael Guardiola, Madrid: Antonio Machado Libros, 2004; citamos por el original inglés).

17. MWM, pp. 198-200.

18. Cavell afirma que a la obra de arte se la reconoce como tal al experimentarla como un "objeto sentido" (y no meramente "sensible"); es decir, como un objeto que suscita una respuesta emotiva. Cfr. MWM, p. 192. 
normal reserva sólo a otras personas - y [los tratamos] con el mismo tipo de desdén e indignación. Significan algo para nosotros, no sólo del modo como lo hacen los enunciados, sino como lo hacen las personas ${ }^{19}$.

La obra artística se convierte por ello en paradigma y expresión del carácter intencional, cargado de sentido, de la vida y la acción humanas ${ }^{20}$, lo cual explicaría la especial importancia que otorgamos al arte.

En consecuencia, el juicio estético sobre la calidad de la obra artística conlleva siempre un juicio ético sobre las intenciones del artista. Cavell se atiene a la caracterización ofrecida por G. E. M. Anscombe ${ }^{21}$, según la cual la intencionalidad implica conocimiento y voluntad, siendo "intencional" la consecuencia de una acción que es sabida y querida por el agente. Dicha intención ha de ser realizada por la acción y quedar manifiesta en los resultados o productos de ésta. Esto hace de la creación artística un acto análogo a la acción ética, también intencional; y no así, por contra, al acto lúdico del juego (cuyo rango de posibilidades de acción, y sus consecuencias, están rigurosamente delimitadas por unas reglas dadas, lo que minimiza su carácter intencional) ${ }^{22}$.

Con ello, Cavell se opone a la posición "objetivista" de Beardsley y Wimsatt ${ }^{23}$, quienes consideraban una "falacia" todo juicio sobre intenciones del autor en materia de arte y estética, primando, en cambio, la atención al objeto artístico en sí mismo, y que por ello, se habían opuesto, precisamente, a las críticas dirigidas por Cavell a la música de vanguardia. Inevitablemente, el juicio sobre obras de arte será un juicio de intenciones artísticas, análogo a un juicio moral; por lo cual, el planteamiento de Cavell aspira declaradamente a una "moralización" de la estética, como bien ha señalado Gordon C. F. Bearn ${ }^{24}$. Esto no implica que Cavell simplemente renuncie a la tradicional autonomía de la esfera estética, ni que niegue su diferencia con respecto a la esfera ética. Al contrario, Cavell subraya esa diferencia; pero de ella no deduce que el acto de creación artística goce de la exención de toda responsabilidad, como tendería a sostenerse, por

19. MWM, pp. 197-198

20. MWM, pp. 227-229.

21. Anscombe, G. E. M., Intention, Oxford: Blackwell, 1956 (versión castellana: Intención, Barcelona: Paidós, 1991).

22. MWM, pp. 236-237.

23. Beardsley, M. C. y Wimsatt, W. K., "The intentional fallacy" (en Wimsatt, W. K., The Verbal Icon: Studies in the Meaning of Poetry, Kentucky: University of Kentucky Press, 1954). "A matter of meaning it" es, en buena parte, una respuesta de Cavell a las objeciones que había presentado Beardsley (y también, desde otra perspectiva bastante distinta, Joseph Margolis) contra sus reflexiones sobre la vanguardia musical en "Music discomposed".

24. Bearn, G. C. F., "Staging authenticity: A critique of Cavell's modernism", Philosophy and Literature, vol. 24, n. 2 (October 2000), pp. 307, 309. La declaración de Cavell está en MWM, p. 178. También suscribe este proyecto "moralista" el joven Fried, que proclama: "El crítico formal de la pintura moderna es también, pues, un crítico moral" (Fried, M., Art and objecthood, p. 219), trastocando así, paradójicamente, las premisas del formalismo. 
ejemplo, desde posiciones formalistas. Pues paradójicamente, da lugar a un incremento en la carga de responsabilidad adquirida por el artista sobre su acto creativo y sobre el resultado de éste: "La creación de arte, al ser conducta humana que afecta a los otros, tiene los compromisos que tiene cualquier conducta. Escapa a la moralidad; no, empero, evadiéndose del compromiso, sino en la libertad para escoger sólo los compromisos en que desee incurrir" 25 .

Según Cavell, la acción ética es algo en lo que todo ser humano se encuentra siempre ya implicado, y que conlleva una serie de compromisos que el agente contrae de modo inevitable y, por así decir, involuntario; se realiza en unas condiciones dadas, no plenamente elegidas; y sus consecuencias se extienden más allá de su resultado inmediato y, posiblemente, del alcance de las intenciones del agente. Todo ello limita la responsabilidad de éste a ciertos aspectos y consecuencias de su acción moral; y, a la hora de enjuiciar moralmente sus faltas, aunque no constituya un atenuante, sí abre la posibilidad de la disculpa, de la enmienda de la conducta futura, y del perdón ${ }^{26}$. En la acción ética cabe hablar de consecuencias no intencionadas; y Cavell considera prueba de ello ciertas conductas y palabras de azoramiento y disculpa que manifiestan claramente la actitud del agente respecto a aquéllas; mientras que la responsabilidad contraída sobre las consecuencias intencionadas está relacionada con una actitud de "reconocimiento" por parte del agente (noción central para Cavell, sobre la cual volveremos más adelante).

Pero en el acto creativo no sucede así: es un acto radicalmente libre, que sólo realiza quien libremente decide ponerse en juego a sí mismo como artista. En él, todo depende de la elección del artista, que elige también qué compromisos desea contraer (qué problemas artísticos se propone abordar); y no sólo cuenta que se satisfaga el compromiso contraído (que el problema artístico que asume el artista quede de algún modo "resuelto" en su obra), sino también de qué modo y con qué recursos se resuelva. Además, según Cavell, las consecuencias del acto creativo quedan totalmente "descargadas" en su propio resultado inmediato, la obra artística; por ello, a su autor se le puede imputar hasta la última de tales consecuencias (es decir, hasta el último rasgo y connotación de su obra), repercutiendo ello en la cualificación ética que reciba el autor, sin que quepa posibilidad de enmienda. Todo ello hace al autor tanto más responsable en caso de que se pueda juzgar que su obra no ha estado a la altura. Las intenciones del artista pueden ser siempre sometidas a examen por escrutinio de su obra, y en principio casi todo lo que un intérprete competente, en un escrutinio interpretativo, encuentre en la obra, podrá serle imputado al artista, y señalársele a éste y al público su relevancia.

25. MWM, p. 199.

26. MWM, pp. 230, 233-234. 
Cavell, inspirándose en Kierkegaard, llega a atribuir al acto creativo en la época moderna rasgos trascendentes, análogos a los de la religión (también la convicción que debe producir la experiencia del arte es análoga a la fe ${ }^{27}$. En la situación modernista, la actividad del artista cobraría, según Cavell, una dimensión heroica y apostólica, pues su tarea es comunicar un mensaje sólo a él revelado, y que no cabe expresar con recursos artísticos tradicionales, dada la situación permanente de crisis artística y cultural, comparable a una crisis de fe religiosa. Ser artista es ahora, quizá, una "vocación" (religiosa); pero no es ya, pues, un oficio, que consista en dominar unas técnicas, y tampoco puede seguir entendiéndose en términos estéticos de "genio". El artista moderno ha de obrar sin ninguna garantía de la posibilidad de comunicarse y compartir esa experiencia con su público (situación que Cavell denomina la "carga del modernismo" ${ }^{28}$ ), porque ya no hay un lenguaje y unos recursos artísticos compartidos y aceptados unánimemente, y porque todo mensaje fácil de comunicar es seguramente banal, y no merece la pena intentar comunicarlo.

El artista, en tanto que autor de su obra, recibe una cualificación ética en términos de "autenticidad" 29 : al decidir libremente ponerse en juego como creador, produciendo una obra y sometiéndola al juicio de una audiencia, ha de mostrar que es un auténtico artista, comprometido con la tradición (aunque critique las convenciones recibidas a través de ella), y que está a la altura de las elevadas exigencias que ella impone. Esto remite a dos aspectos cruciales de la actividad creativa. Primero, la sinceridad: la creencia del artista en la validez del medio artístico en el que trabaja y de los recursos que éste le ofrece. Pero eso no basta: es necesaria además la "seriedad", que es un firme compromiso del autor con la pretensión de relevancia artística de su obra. Con la dificultad añadida de que en la situación modernista, según Cavell, no hay criterios seguros para saber cuándo esa sinceridad y seriedad efectivamente se dan:

Ya no podemos estar seguros de que un artista sea sincero: no tenemos convenciones o técnicas o recurso alguno en que podamos seguir confiando: cualquiera podría falsificarlo. Y esto significa que el arte moderno, si y allí donde existe, fuerza la cuestión de la sinceridad, privando al artista y a su público de toda medida excepto la atención absoluta a la propia experiencia y la absoluta honestidad al expresarla. Esto es lo que quise decir cuando dije que [el arte moderno] pone al descubierto la condición del arte en general ${ }^{30}$.

27. El texto clave a este respecto es Cavell, S., "Kierkegaard's On authority and revelation" (MWM: 163-179), un comentario al libro de Kierkegaard citado en el título del mismo. De particular relevancia por lo que hace al arte moderno como apostolado, cfr. MWM, pp. 175179. El asunto reaparece en "Music discomposed" en relación con la obra de arte como "objeto sentido", MWM, p. 191.

28. MWM, pp. 180, 187, 207.

29. MWM, pp. 203, 211-212.

30. MWM, p. 211. 
En el contexto de la situación modernista, la autenticidad y seriedad exigen del artista que sea agudamente consciente de la crisis de los criterios y procedimientos heredados por tradición, y que, a pesar de las dificultades que ello plantea, se comprometa firmemente con el enriquecimiento y desarrollo artístico de dicha tradición. Ello implica una doble tarea. Por un lado, asumir el reto de proponer soluciones a los problemas artísticos planteados por el arte más reciente; por otro, poner al descubierto, a través de sus obras artísticas, los criterios en virtud de los cuales se reconocen los objetos como ejemplares de un determinado medio artístico, y por tanto, como objetos artísticos a secas; lo cual exige no dar por sentado los criterios tradicionalmente heredados para discernirlo, sino más bien, ponerlos en cuestión mediante la obra producida ${ }^{31}$.

Desde la perspectiva de la producción, el acto creativo es para Cavell "composición". Cavell usa ese término en un sentido amplio, que no se refiere exclusivamente al formato peculiar de objeto artístico correspondiente al medio específico del arte musical, ni tampoco a un modus operandi específico de dicho arte. Componer, en cualquier arte, sería el acto intencional y libre de crear un objeto artístico. El acto compositivo implica tomar decisiones y afrontar riesgos, haciéndose el autor personalmente responsable del resultado, y de ese acto forman parte constitutiva las nociones de "azar" e "improvisación", que serían "virtudes prácticas", al igual que en la acción ética; pues permiten franquear con éxito la distancia que media entre la intención y la realización, superando las impredecibles dificultades que se presenten ${ }^{32}$. Esta faceta de la concepción caveIliana de la creación artística tiene similitudes con la noción de sabiduría práctica en Aristóteles ${ }^{33}$, al tiempo que incorpora la exigencia "modernista" de innovación.

Improvisación y azar introducen en toda creación artística un elemento de sorpresa y de lo involuntario; aunque para Cavell es aún más profunda y originaria la libertad que conlleva, por sí mismo, el acto compositivo de creación, con independencia de la medida en que intervengan en él azar e improvisación. Cavell define la "improvisación" como la virtud de la riqueza en recursos e inventiva, que permite prever las dificultades de la actividad creativa emprendida en unas circunstancias dadas 34 . Y el "azar" o "riesgo" (chance, que en la frase in-

31. Eso no quiere decir que el artista convierta su obra en un discurso teórico, ni que escriba ensayos sobre el tema.

32. MWM, p. 198.

33. Hay también una gran cercanía de Cavell al Heidegger de Sein und Zeit, no sólo en la reelaboración de nociones de la filosofía práctica aristotélica como determinaciones ontológicas del ser humano, sino también en la importancia que atribuye a la idea de "autenticidad" en el modo de vivir y obrar. Cfr. MWM, p. 198, 325 n 15.

34. La noción cavelliana de "improvisación" es muy ambigua (más abajo veremos las críticas que ha recibido). Cavell parece querer darle un sentido genérico, aplicable a todas las artes; pero no es fácil entender cómo, ya que la plantea en estrecha referencia a las artes escénicas y la noción de "ejecución" o "interpretación" (Cfr. MWM, pp. 200-202). 
glesa to take chances quiere decir "arriesgarse") sería la capacidad de afrontar el riesgo de fracaso y de sacar partido de las situaciones surgidas de improviso, incluso si son difíciles; esta noción se refiere a la dificultad de la elección del curso de acción en situaciones imprevistas. Según Cavell, para hablar de improvisación o azar no basta que la obra sea "abierta", que alguno de sus aspectos concretos quede indeterminado o inacabado; y no necesariamente estas nociones se circunscriben a lo que propiamente se entiende por "improvisación" en las artes escénicas (realizar algo sin partitura, guión, preparación ni directrices previas). Los elementos de origen "improvisativo" en la obra deben verse expresados en ésta bajo la forma de un cierto "sonido, carácter o tono improvisativo" claramente reconocible para el espectador, de modo que el crítico ha de poder identificarlos en un análisis estético de su experiencia de la obra, guiándose por su propia respuesta personal a ella y sin recurrir al conocimiento histórico de su proceso real de génesis ${ }^{35}$. Así, improvisación y azar, al formar parte del proceso creativo, pueden quedar reflejadas en una obra que, no obstante, está totalmente acabada, otorgando a ésta una impresión de espontaneidad, que, según Cavell, es consustancial a toda experiencia del arte (aunque luego veremos que al invocar estas dos nociones, Cavell tiene en mente un tipo de práctica musical bastante más concreta de lo que podría parecer).

Desde la perspectiva de la recepción, la responsabilidad del acto creativo del artista significa que, al proponer la experiencia de su obra como producto acabado, el artista invita al espectador a compartir los riesgos contraídos por él en virtud de su libre decisión de afrontar ciertos problemas artísticos, de elegir ciertos medios y recursos para resolverlos. Implica, por tanto, que el artista tiene la obligación de justificarse ante el espectador como creador; y debe hacerlo mostrando, en la experiencia que el espectador tiene de la obra, que correr esos riesgos ha merecido la pena ${ }^{36}$.

\section{El medio artístico como pluralidad aplicada}

En la crítica y la teoría del arte anglosajonas del siglo XX ocupa un importante lugar la reflexión sobre qué sea el "medio" específico con el que operan las distintas prácticas o tradiciones artísticas (sean éstas la pintura, escultura, arquitectura, etc., establecidas en el "Sistema de las Artes" desde el S. XVIII, u otras de

35. Esto pone en entredicho el enfoque, propuesto por J. J. Nattiez, de la "poiética inductiva", que precisamente se centraría en reconstruir, a partir de la obra acabada, las estrategias técnicas y recursos artísticos puestos en juego por el artista en el proceso de su producción; y ello, no como interpretación meramente ficcional, sino con cierta aspiración a reconstruir la realidad de dicho proceso (cfr. Nattiez, J. J., "De las artes plásticas a la música: Pierre Boulez, a la escucha de Paul Klee", Bajo Palabra, II Época, no 7, (2012), pp. 125-127; Nattiez, J. J., Musicologie générale et sémiologie, París, Christian Bourgois éditeur, 1987, pp. 177-178).

36. MWM, p. 199. 
carácter mixto o de nueva aparición), e incluso, el debate sobre sí puede realmente hablarse de un tal medio específico para cada una de las artes. Esa reflexión se vio impulsada por las vanguardias históricas, pues se entendía que éstas ponían en cuestión la definición y límites tradicionalmente establecidos para los medios artísticos de las diversas artes. Distintos críticos y teóricos contaron, en su discurso, con distintas nociones de "medio artístico", de modo implícito unas veces, y más explícito otras. En los textos de la época temprana que nosotros analizamos, Cavell esboza una peculiar concepción del medio artístico, que más tarde seguirá desarrollando en sus estudios sobre el medio cinematográfico.

Cavell rechaza la noción de "arte en general": una obra de arte, si ha de ser tal, debe pertenecer a un medio artístico determinado, como también sostuvieron los formalistas. Sin embargo, Cavell no asume el planteamiento formalista de la noción de "medio", que él conoce en la formulación de Greenberg, purista, reduccionista, y esencialista. Greenberg adoptó el criterio formalista de vincular cada arte exclusivamente a un canal o esfera sensorial, prohibiendo a cada una de las artes todo recurso no ligado a su esfera sensorial correspondiente; y eso le llevó a concebir el medio artístico de las diversas artes como un invariante ahistórico, y a postular un proceso reduccionista de simplificación y depuración de las diversas artes ${ }^{37}$. En cambio, Cavell no adopta el criterio formalista de esferas sensoriales, y su planteamiento es más abierto y complejo, aunque su desarrollo teórico a nivel general es también más circunspecto (ya que la tarea sería entrar a examinar el caso particular de cada arte en su concreto desarrollo histórico). Cavell entiende un "medio" artístico como un plexo de convenciones que regulan la aplicación concreta de múltiples procedimientos y recursos según unos criterios. Dichas convenciones son normas y condicionantes heredados por tradición y por un contexto histórico compartido comunitariamente, que aportan al artista un marco para su actividad creativa: unos materiales, unos procedimientos para su empleo, unos recursos, así como una serie de problemas ${ }^{38}$.

La concepción cavelliana del medio artístico es historicista. No concibe los medios artísticos como esencialidades inamovibles, sino como realidades culturales complejas que cambian a lo largo de la historia. Admitiendo esta mutabilidad histórica, en el arte que podríamos Ilamar "clásico", anterior a la época moderna, el medio de un arte podía mantener una concreción relativamente estable y unitaria durante largos períodos; en ese contexto "clásico", un medio artístico era algo "uno", de lo que cabían varias "maneras" o "estilos" de realización, los cuales distinguían a los diversos artistas sin que por ello dejaran de trabajar todos ellos con el mismo "medio". Pero en el arte moderno, el medio de un arte no es ya algo de lo cual existan varias maneras o estilos de realización, sino algo que ha de ser redescubierto o reinventado nuevamente por cada

37. Cfr. Greenberg, C., "Modernist Painting" [1960], Collected Essays, vol. IV, pp. 85-93.

38. MWM, pp. 270-271, 276-277. 
artista en cada obra ${ }^{39}$; pues lo que resulta convincente en una obra puede no ser capaz de suscitar convicción en obras sucesivas. Ese descubrimiento es un "reconocimiento" 40 de una u otra convención del medio: recursos, aspectos del proceso técnico, modos de organización. Pero más que el propio rasgo, recurso o convención que es en cada caso objeto de reconocimiento, lo importante es el modo como el artista lo reconoce en su obra, cómo lo usa en ésta para que logre ser convincente. Sería esto (y no una diferencia de "estilos" de realización) lo que distingue el toque personal de cada artista moderno.

La modernidad artística sería, pues, la época histórica en la que las diversas artes se plantean la cuestión de qué sea lo constitutivo de sus respectivos medios. Cada obra de arte moderna, implícitamente, viene a proponer una respuesta a la pregunta por la naturaleza del medio propio de la práctica artística a la que pertenece. Una respuesta paradójica, cuya pretensión es redescubrir lo que en cualquier momento, desde siempre, ha sido esencial para identificar el medio; pero que de hecho, redescubre esa esencia siempre desde la concreta perspectiva del momento histórico en el que se formula. Por lo cual, en otro momento histórico, bajo una distinta situación de desarrollo del arte, en la cual se planteen problemas artísticos distintos, la respuesta a esa misma pregunta podría ser muy diversa. Y en la época premoderna, cuando la continuidad espontánea de la tradición aseguraba la identidad del medio para cada práctica artística, para tal pregunta simplemente no había lugar.

Todo medio artístico tiene, según Cavell, sus "automatismos" operativos en el proceso de realización de la obra de arte ${ }^{41}$. El automatismo es aquél aspecto del medio artístico que funciona sin la intervención física o "manual", ni voluntaria, del artista. En la época del arte moderno surgen medios artísticos nuevos (fotografía, cine), basados en un "aparato", o dispositivo tecnológico de funcionamiento mecánico, donde esos automatismos realmente se emancipan de la intervención personal y física del artista. Pero también los medios y prácticas artísticas arte más tradicionales poseen cierto tipo de automatismos ${ }^{42}$. El automatismo hace posible que la belleza de la obra de arte sea semejante a la de la

39. Afirma Cavell que "Un medio de la pintura no es una manera en la que [la pintura] se hace, sino su descubrimiento" (TWV, p. 240 n 42).

40. "Reconocimiento" es una importante y difícil noción cavelliana (aunque de raíz wittgensteiniana). Se refiere a una modalidad epistémica que no es propiamente conocimiento: no tiene el alcance y firmeza de éste, ni está sometida a sus requisitos. Aquello que es objeto de reconocimiento (por ejemplo, la existencia de otros sujetos ajenos a mí) no es algo que pueda ser conocido; no pede lograrse certeza respecto a ello, y siempre cabe el falseamiento, la impostura o el error. Pero dicho reconocimiento permite al ser humano superar sus limitaciones cognoscitivas, haciéndose cargo entre otras cosas, precisamente, de las condiciones de su propia finitud. Cfr. MWM, pp. 277-78, 279, 325; TCR, pp. 357-358.

41. "Usar automatismos para crear cuadros es lo que los pintores siempre han hecho" (TWV, p. 108).

42. TWV, p. 108. 
naturaleza, y contribuye también a que la obra alcance su "cierre", su acabamiento o compleción final, merced al cual el artista, convertido en primer espectador y juez de la obra, la da por apta para mostrarla ante el público.

Cada arte o medio artístico poseería un peculiar modo de darse, o present$n e s s^{43}$, que le sería propio. Se trata del modo, específico para cada medio artístico, en el que todo cuanto constituye el significado de una obra y le confiere valor artístico, cuanto el artista se ha propuesto y ha logrado realizar con ella, se ofrece plenamente (sin ambigüedades ni opacidad) a aquel espectador atento, que es capaz de elevarse sobre las múltiples contingencias que afectan y condicionan la situación de recepción de la obra (el artificio de la ficción, la teatralidad de la puesta en escena) y que está a la altura de su encuentro con ella. Si esto acontece, la obra logra superar (pero no necesariamente "suprimir") su condición "literal" de mero artefacto material. Cavell intenta precisar en qué consista la presentness para el caso particular de diversos medios artísticos, aunque en cada caso se refiere a aspectos de esos medios que son distintos, y hasta contrapuestos $^{44}$. La presentness tiene una estrecha relación con el peculiar quid constitutivo de cada uno de los medios artísticos; es ese quid lo que hace que la obra de arte realizada en un determinado medio sea capaz de la plena donación de su significado que constituye la presentness; y ésta, a su vez, se encuentra vinculada a la capacidad de suscitar en el espectador la convicción sobre el genuino valor artístico de la obra. Pero además, la total apertura de la obra al espectador implica al mismo tiempo, paradójicamente, un radical cierre e independencia ontológica de la obra respecto al propio espectador y al contexto institucional de exhibición, en el que se produce el encuentro entre obra y espectador ${ }^{45}$.

Puesto que la noción genérica de "Arte" implica para Cavell necesariamente su particularización en diversos medios artísticos concretos, la pregunta moder-

43. De este neologismo inglés, acuñado por Michael Fried, y adoptado también por el propio Cavell, no cabe traducción precisa al castellano. En los textos de Fried, quien lo desarrolla ampliamente en referencia al medio pictórico y en su polémica contra el arte Minimal, suele aparecer contrapuesto a presence (cfr. Fried, M., "Art and objecthood", en Art and objecthood, pp. 148-172). Y Fried también sugiere que no necesariamente está ligado al presente temporal como "ahora", por lo que, en realidad, "presencia" o "presente" no sirven para traducirlo.

44. En el caso del medio pictórico, por ejemplo, su presentness estaría fundada en el carácter plano y delimitado del soporte del cuadro de caballete, que hace accesibles de una ojeada todos sus contenidos plásticos, y por tanto, el significado expresado mediante ellos; esto vincularía la presentness en ese medio artístico al modo temporal de la instantaneidad. Sin embargo, como ya señalamos, para Michael Fried, interlocutor y también mentor de Cavell en materia de artes plásticas, la cosa es mucho más complicada, pues niega que pueda identificarse la forma de presentness del medio pictórico con la modalidad temporal del presente instantáneo.

45. TWV, p. 111. Obviamente, esto va a la contra de las ideas sobre la "obra abierta" que tanto circulaban en la época de los ensayos tempranos de Cavell, y de ciertas prácticas a las que esas ideas dieron pie. 
nista por qué sea en general "arte" sólo será genuinamente artística si se plantea como pregunta sobre qué sea un arte en particular, como interrogación sobre los límites dados y heredados de ese arte en particular. Implica poner en juego criterios; pero los criterios sólo existen en el marco específico de cada una artes singulares: sobre el "arte-en-general", considerado abstractamente, no hay criterios:

Si existe una respuesta clara a la cuestión: “¿es esto música (pintura, escultura...)?", entonces la cuestión de si algo es arte resulta irrelevante, superflua. Si esto es música, entonces (analíticamente) esto es arte. Esto parece desprejuiciado. Pero la negación no lo parece: si esto no es música, entonces esto no es arte. Pero, ¿por qué esto resulta prejuicioso? ¿Porqué no podemos dejar que el Pop Art, digamos, o los espectáculos de Cage, o los happenings, sean entretenimientos de algún tipo sin preocuparnos por el arte? Pero nos preocupamos ${ }^{46}$.

Por ello, Cavell rechaza ciertas teorías y prácticas del arte de vanguardia, que proponen una redefinición "ampliada", tanto del arte en general, como de alguno de los medios artísticos en particular" ${ }^{47}$. Tacha despectivamente de "modernizadores" (que no "modernistas") a estos ultra-vanguardismos, que prescinden de toda tradición y de entrada aspiran a situarse más allá de ella. Sus supuestas "ampliaciones" del arte serían meros subterfugios para eludir el problema de la sospecha de la fraudulencia inherente a la experiencia moderna del arte mediante el fácil expediente de legitimar artísticamente, de antemano, cualquier innovación arbitraria, prescindiendo así de toda limitación, pero sin afrontar el problema de qué sea legítimo como arte en general y, por tanto, qué sea legítimo dentro de algún medio artístico en particular. Para Cavell, por el contrario, la seriedad de una obra de arte, de un artista, y de un teórico del arte radican justamente en afrontar dicho problema, y en hacerlo aceptando unos límites; límites que ciertamente no son apriorísticos ni ahistóricamente fijos, pero que tampoco pueden suprimirse a voluntad.

Aquí es de importancia la noción de "teatralidad": un término de carga negativa, ligado a la problemática sobre el escepticismo y el mundo moderno en los textos filosóficos de Cavell48. "Teatralidad" sería la dolencia ética del moderno sujeto escéptico, que al ver frustrada su pretensión de alcanzar un aseguramiento y control totales para poder escapar a la finitud, sucumbe a la duda nihilista sobre la existencia real del mundo y sobre la humanidad de sus semejantes, y por ello, es incapaz de dar auténtico sentido a su propia vida y acciones cotidianas. Como señala Gordon C. F. Bearn, la teatralidad es una forma de

46. MWM, p. 219.

47. MWM, pp. 214-215, 218.

48. También es noción central en el debate de Fried contra el Minimalismo, y en todos los estudios de historiografía artística que ha publicado este autor a partir de los años 70. 
inautenticidad y falta de seriedad, y está ligada a la indeterminación y la ambigüedad 49 . "Teatral" es el intento servil de acomodar la intención artística a las expectativas de una audiencia (convirtiendo el acto creativo en un simulacro, y su producto en un mero artificio, carente de toda credibilidad); y también es teatral dejar dicha intención ambigua o abierta, eludiendo el compromiso con una intencionalidad determinada. $Y$ en esto incurren quienes intentan redefinir el arte y las artes arbitrariamente, obviando las convenciones implícitas que los limitan, y evitando el compromiso con la situación de crisis de la tradición que conlleva aceptarlas y criticarlas sin renunciar a suscitar convicción.

\section{La música como arte inherentemente dramático}

El planteamiento formalista, que pretende caracterizar el medio de cada una de las artes vinculándolo exclusivamente a una determinada "esfera sensorial", lleva a definir la música, arte de sonidos, como un "arte del tiempo" (en contraposición a las artes plásticas, que serían visuales, y por tanto, "artes del espacio"). Pero Cavell rechaza una caracterización semejante del arte musical, porque sería tan banal como inadecuada (del mismo modo que Cavell no sostiene que todos recursos artísticos que tienen que ver con el tiempo sean espurios para los medios específicos de artes plásticas como la pintura o la escultura).

Hay en Cavell cierta ambigüedad a la hora de especificar su noción de medio para el caso particular del arte musical. En "Music discomposed", explica que el medio de la música vendría a estar constituido por lo que la teoría analítica musical denomina "formas musicales": las grandes estructuras de organización a gran escala de los materiales temáticos, armónicos o rítmicos en la obra (un ejemplo especialmente destacado sería la forma sonata) ${ }^{50}$. Pero en "The avoidance of love", Cavell sugiere que el medio musical es el tiempo, no a secas, sino como "movimiento orientado"; lo que le lleva a proponer una noción de "música" como drama o narración sin palabras ${ }^{51}$.

Como Cavell asume la tesis (de origen formalista) de la constitutiva diversidad de las artes y de sus medios respectivos, su noción de presentness requiere especificación para el caso de cada una de las artes. En relación con la música y el teatro, artes temporales y escénicas, que implican la ejecución o representación en un escenario, la forma de presentness que corresponde a los medios de estas artes implica ante todo al aspecto temporal dramático, dinámico y direccional (y diríase que heroico, trágico, fáustico) que Cavell atribuye a dichas artes. Desde una perspectiva más "formalista", tal vez sería admisible

49. Bearn, G, "Staging authenticity", p. 302.

50. MWM, p. 221.

51. MWM, pp. 320-321. F. Cox, en su resumen de la posición de Cavell, no parece prestar atención a este aspecto del discurso cavelliano sobre la música. 
pensar que ambas artes tienen en común el presentar una sucesión dinámica de estados y coloraciones emotivas diversas, y que su propósito es unificarlas en una organización formal coherente ${ }^{52}$. Pero para Cavell todo esto sólo serían meras propiedades "teatrales" (en un cierto uso peyorativo que hace Cavell del término "teatral") de la obra musical o dramática, que no caracterizan adecuadamente los medios de estas dos artes ${ }^{53}$. Más significativo, en cambio, sería que música y drama teatral comparten dos rasgos fundamentales y característicos de la acción humana. El primero es la temporalidad direccional, orientada desde un pasado rememorado hacia un futuro anticipado y proyectado, los cuales se entrelazan en un presente vivido. El segundo es el hecho de que, de estos tres éxtasis temporales, sólo el presente tiene propiamente existencia "real", y de que es justamente en el presente donde se juega lo decisivo. Por ello, música y teatro, para Cavell, serían una "imitación" de aquellos "hechos de la vida" que hacen de la acción y la vida humanas lo que son ${ }^{54}$. Según esto, cabe entender que, para Cavell, la música es un arte constitutivamente mimético (aunque Cavell no Ilegue a decirlo en esos términos), cuyo objeto de imitación sería la acción humana.

De este modo, Cavell concibe la música como un arte dramático, una especie de "drama sin palabras" (pero no por ello menos narrativo, ni menos vinculado a la representación de la acción humana y sus condiciones ${ }^{55}$ ): "cuando [la] comprendemos, escuchamos la música que nos es más familiar de la misma forma en que seguimos las líneas y acciones en aquel medio que hace de la poesía drama" 56 . Pero Cavell asocia esta constitución dramática de la música a una serie de recursos (armonía funcional, desarrollo motívico, etc.) que son específicos de la música tonal. Dicha constitución dramática del arte musical sólo se encontraría reconoce plenamente operante en aquel tipo de música que emplea esos recursos; y de modo muy señalado, en la forma musical clásico-romántica de la sonata, forma musical a la cual Cavell otorga el estatuto de "medio" del arte musical ${ }^{57}$. En la forma sonata acontecería la más completa realización del carácter dramático del medio musical, y su surgimiento habría sido el acontecimiento histórico que habría permitido al arte musical alcanzar, por vez primera, la "autonomía dramática" (la capacidad de ser dramático, pero mediante sus re-

52. Si bien semejante planteamiento en términos "emotivistas" en realidad no sería muy propio del formalismo.

53. MWM, p. 320.

54. MWM, p. 331.

55. Cavell habla de "drama" en un sentido fuerte, cuyo paradigma serían King Lear y otras tragedias de Shakespeare. Nada que ver, pues, con las "formas móviles sonantes" (tönend bewegende Formen) de un Hanslick, normalmente considerado representante de la teoría formalista musical (aunque algunos intérpretes matizan que el de Hanslick sería un formalismo "dinámico").

56. MWM, p. 352.

57. MWM, p. 221. 
cursos propios). En efecto, cabe pensar que, de entre todas las formas musicales instrumentales, la sonata, estrechamente vinculada a la armonía tonal funcional, es la más "narrativa"; y los orígenes tanto de la tonalidad como de la armonía funcional están vinculados a los intentos de restaurar el teatro griego que darían lugar al moderno género operístico como drama in música, a comienzos del siglo XVII. Para Cavell, el logro de la autonomía dramática mediante la forma sonata habría supuesto para el arte musical un claro progreso con respecto a etapas históricas anteriores, en las que dicho arte se encontraría en un grado inmaduro de desarrollo, y también en una dependencia servil con respecto a otras artes, sobre todo las del lenguaje verbal.

Queda así definida la tarea del arte moderno para el medio musical como la búsqueda de aquello que, por ser fuente de experiencias de presentness (en el sentido ya mencionado de direccionalidad cargada de sentido, que según Cavell es como se especifica este concepto para el arte de la música), hace que el flujo de sonidos sea convincente como "música"58. Ello es, para Cavell, un aspecto hasta tal punto constitutivo del medio musical que se identifica con el propio arte de la música. Y esta identificación cobra alcance suprahistórico; pues, aunque históricamente puedan ir variando los recursos concretos que se usan en la práctica musical, y mediante los cuales, por tanto, se intenta producir la presentness que a la música le es característica, lo que nunca cambiaría es que, allí donde hay música, siempre ha de haber presentness, en el sentido de flujo direccional del tiempo y de los eventos musicales. Preguntarse por la esencia del medio musical es preguntarse por aquello que es constitutivo de la presentness (en el mencionado sentido dramático-dinámico y narrativo) de la sucesión temporal de sonidos.

Un rasgo característico del medio del drama teatral (y podemos entender que también del musical) consistiría en mantener en todo momento siempre a la vista del espectador toda la evidencia relevante para el desarrollo y desenlace de los acontecimientos trágicos; de modo que la incapacidad del espectador para hacerse cargo de esas evidencias es un rechazo o incapacidad culpable de ver, que le sitúan en la misma posición y el mismo error que el personaje trágico y le hacen cómplice de éste en el carácter fatal de los hechos dramáticos ${ }^{59}$. En virtud de ello, Cavell atribuye al drama unas claras implicaciones éticas, inscribiendo así su concepción del drama en su proyecto "moralizador"60.

58. Se podría decir "cavellianamente" que fue esto lo que Schoenberg se propuso lograr con medios "armónicos" atonales: mantener la direccionalidad "narrativa" de la música en ausencia de la armonía funcional y tonal, preservando recursos como el desarrollo motívico e, incluso, la forma "sonata". Sus sucesores serialistas de la vanguardia de Darmstadt no se propusieron tal cosa, y no es de extrañar que no cuenten con el aprecio de Cavell.

59. MWM, p. 313.

60. MWM, 282, 319, 331-4, 339. 


\section{Las críticas de Cavell a la música de vanguardia}

Es sobre todo en dos de sus textos de los años 60, "Music discomposed" y "A matter of meaning it", donde Cavell habla explícitamente de las corrientes de la música de vanguardia de aquella época y formula sus críticas contra ella. Al hacerlo, adopta una posición que es simultáneamente la del filósofo esteta y la del crítico. Pues para Cavell, la disciplina de la Estética es lo que podríamos Ilamar una "metacrítica" o metadiscurso de la crítica de arte. La Estética, según Cavell, no atiende directa ni exclusivamente a las obras artísticas mismas, ni a su proceso de producción, sino que tiene en cuenta la previa mediación del discurso crítico sobre aquéllas, y es el discurso crítico lo que toma como "dato"61. La Estética es, pues, un discurso que versa inmediatamente sobre otros discursos, y sólo indirectamente sobre "objetos". Por ello, cuenta con un "canon de crítica": discrimina entre los discursos críticos que son relevantes y los que no lo son, entre críticos de arte competentes e irrelevantes. Y, al igual que la crítica, la Estética emite dictámenes críticos y valorativos sobre las obras de arte ${ }^{62}$, estableciendo también un canon de dichas obras. A la hora de juzgar obras de arte, Cavell concede gran importancia a lo que sobre las obras y sus autores dicen los críticos, e incluso, dado el caso, los propios artistas. Eso es lógico, dado que para Cavell lo que ha de valorarse son las intenciones del artista, y la autenticidad o inautenticidad de éste como creador y de su obra como contribución a la tradición.

En cuanto a la crítica de arte propiamente dicha, para Cavell, el dato del que debería partir no sería tanto la propia obra como objeto, y menos aún los procesos técnicos y recursos artísticos empleados en su producción, sino más bien la "respuesta" subjetiva del propio crítico a ella; y su juicio tendrá inevitablemente que dictaminar sobre las intenciones del artista y su autenticidad. En cambio, Cavell sugiere que en condiciones normales, quienes ejercen la crítica y producen discursos sobre el arte, no deberían, en general, ser artistas, y sobre todo, no deberían ser practicantes del mismo arte cuyos objetos critican:

... difícilmente puede uno imaginar una revista seria en la que colaboraran poetas, novelistas o pintores importantes, dedicada a los problemas de hacer poemas y novelas y pinturas, ni que un artista tal pudiera encontrarla útil si de algún modo apareciera. Incluso podría ser considerado por ellos inaudito el airear estos problemas en público, y en el mejor de los casos, distrae de la tarea de llevar adelante el verdadero trabajo. Las revistas están para dar entrevistas o publicar el trabajo de uno, y hacer que otros escriban sobre él. [MWM: 186]

61. MWM, pp. 182, 184.

62. MWM, pp. 180-181. 
Ello se debe a que Cavell atribuye a la obra de arte al estatuto de producto intencional, y por tanto, de objeto "ya hablado" (already spoken): el artista ya ha dejado dicho en su obra todo lo que ha de decir; y todo lo demás que quepa decir, si lo hay, es sólo tarea del crítico (y del esteta) el decirlo ${ }^{63}$.

Pero esto no parece corresponderse con la situación real en el caso particular de la Nueva Música, donde acontece un modo, al parecer anómalo, de intervención del compositor en el discurso teórico y estético. Es piedra de escándalo para Cavell el cariz que había venido tomando el discurso sobre música en general, ya sea teórico, crítico o incluso historiográfico (señala con preocupación que "las historias de la música no contienen prácticamente ninguna crítica o valoración de sus objetos, sino que se concentran en detalles de su notación o su instrumentación o en las ocasiones en que fueron interpretados"64). Cavell cree que esto está vinculado al anómalo modo de intervención del artista compositor en el discurso crítico y estético sobre la música de vanguardia. Para Cavell, esa anomalía tendría un carácter sintomático, pues señalaría a algo profundamente problemático en la propia vanguardia musical, en la cual se manifestaría la misma amenaza constitutiva de fraudulencia que afecta a todo el arte moderno, pero de un modo, según parece sugerir Cavell, más agudo, o más ostensible, que en otras artes ${ }^{65}$.

Cavell tiene aquí en su punto de mira publicaciones como Die Reihe o Perspectives on New Music, que habían surgido con la expansión de la vanguardia musical en los medios académicos norteamericano y europeo, y se habían erigido en portavoces de la vanguardia musical y en escenario de las intervenciones teóricas de sus compositores más destacados (Stockhausen, Ligeti, Boulez, Babitt...). Pero que eran al propio tiempo revistas académicas de teoría musical "analítica" (de orientación técnico-formal, pero no valorativa); disciplina que algunos de esos compositores vanguardistas también practicaban, y contra la cual Cavell expresa serios reparos, cuando considera que el alto grado de desarrollo del lenguaje analítico y de la notación musical tal vez sea más un mal que un bien, y se lamenta de la "carencia de una crítica humana": por causa de ello, el discurso crítico y estético sobre la Nueva Música sería incapaz de "articular una respuesta a una pieza musical"66.

63. Cavell silencia el contraejemplo insoslayable de las "revistas de vanguardia" y los "manifiestos" de la época de las primeras vanguardias históricas. Más aún, desde la perspectiva del propio Cavell, la situación moderna del arte, que motiva una creciente reflexividad de la práctica artística, parecería otorgar legitimidad a la figura del artista que ejerce como teórico. Y, sin embargo, Cavell no termina de aprobar esa figura, que él encuentra sospechosa (cfr. MWM, pp. 186-188). Por eso no estamos de acuerdo con Bauer "Cavell and the Critique...", pp. 75-76), quien parece atribuir a Cavell la idea de que el propio artista modernista debe proporcionar un discurso de "justificación filosófica" de su obra, e incluso, incluir tal justificación como elemento componente de sus obras.

64. MWM, pp. 185-186.

65. MWM, pp. 186-188, 196, 207.

66. MWM, pp. 185-186. 
Basándose en su concepción "dramática" del arte musical, Cavell ofrece un diagnóstico de la dificultad de la música de vanguardia para las audiencias actuales. Según él, el motivo profundo de esa dificultad, en realidad, no radicaría en una falta de familiaridad de la audiencia con los nuevos modos de organización del material melódico, armónico y rítmico, ni en que el alto contenido interválico disonante de esta música pueda resultar chocante. Radicaría más bien en la pérdida de la direccionalidad dramática de los eventos melódico-armónicos que caracteriza a la música tonal67, y que, según el planteamiento de Cavell, constituye la forma de presentness específica del arte y el medio de la música:

En mi experiencia, este tipo de escucha ya no es totalmente posible con la desaparición de la tonalidad - quizás sea esta presentness continua la que echamos de menos en las dificultades de la música post-tonal, más que su carencia de melodías y armonía, pulso y ritmo. [...] Esto sugiere que la fidelidad al arte de la música no se expresa en un esfuerzo, como pudiera formularse, por encontrar modos de organización basados en el sonido mismo (una forma de hablar que podría describir cualquier música, o ninguna música en absoluto), sino en descubrir qué hay en los sonidos sucesivos que en cualquier momento les ha permitido ser percibidos como presentness ${ }^{68}$.

Cavell entiende que la vanguardia musical de los años 50 y 60 había asumido una concepción trivialmente inerte y "formalista" de la música y de su medio artístico, formulada en términos de "organización del espacio sonoro" 69 , y que sus representantes más acérrimos erraban al proponerse como tarea la "ampliación" de dicho espacio con nuevos materiales y con nuevos procedimientos para organizarlos. Por el contrario, Cavell rechaza aquella concepción, la cual desatiende por completo la peculiar forma dramática que, según él, hace posible la plena donación del significado de la obra en el medio musical (no en balde los compositores de vanguardia de la época abjuraban de géneros como la ópera y formas musicales como la sonata clásica, los cuales consideraban ana-

67. Este diagnóstico es similar al ofrecido por Leonard B. Meyer, con sus observaciones sobre la "semántica interna" del medio musical, en textos de los años 50 y muy a comienzos de los 60. En esa etapa, Meyer había sostenido una posición "humanista" cercana a la de Cavell (a excepción del compromiso "modernista", que es ajeno a Meyer). A la vista de ello, resulta notorio el contraste entre la posición cercana al postmodernismo que terminaría adoptando Meyer a partir de mediados de los años 60, y el eticismo humanista al que se mantendrá adscrito Cavell. Cfr. Diaz Soto, D., "Stasis, saturación cultural, pérdida de presencia", Bajo Palabra, 2a Época, no 3 (2008), pp. 25-34.

68. MWM, pp. 352-353.

69. MWM, pp. 221-222.

70. Más tarde cambió la situación, y algunos de esos compositores vanguardistas, como Ligeti o Stockhausen, hicieron tentativas de remozar el género operístico (y no meramente el "teatro musical"). 
crónicos $\left.{ }^{70}\right)$. Y en consecuencia, considera artísticamente espuria esta presunta tarea.

Asimismo, Cavell acusa a la "filosofía" vanguardista de la "nueva música" y a las prácticas musicales asociadas a ella de haber eliminado el acto compositivo, en tanto que acto de creación libre, intencional y responsable, con el componente espontáneo de genuino "azar" e "improvisación" consustancial a dicho acto $^{71}$. En la música de vanguardia, el artista abdicaría de su condición de agente y autor, para tornarse en mero intermediario de una suerte de autopoiesis de la obra, de carácter impersonal y literalmente "mecánico", ya sea mediante un proceso aleatorio o mediante unas reglas generativas exhaustivas estipuladas de antemano. El genuino acto compositivo de creación quedaría reemplazado, bien por unas nociones y prácticas pervertidas de "azar" e "improvisación" que niegan toda implicación del artista en una actividad compositiva (en las prácticas musicales aleatorias), o bien por un concepto mecanicista de la composición como "organización total" (en las de tendencia serialista). Pero estas nociones y prácticas no corresponderían a las genuinamente artísticas y musicales (es decir, las que propone Cavell), porque eliminarían la relación intencional entre el artista y su obra ${ }^{72}$.

Así, la noción de "aleatoriedad" de la "nueva música" sería una espuria corupción de las genuinas virtudes creativas del azar y la improvisación: ofrecería al artista una fantasía absurda de libertad total, prescindiendo de todo auténtico horizonte de convenciones y posibilidades delimitadas compartido por una comunidad viva. Al pretender crear una comunidad de oyentes ex novo en el mismo instante de su realización, la acción creativa carecería, según Cavell, de cualquier objetivo reconocible como tal, resultando absurdo hablar del riesgo de errar, de incidencias en el curso de acción, o de capacidad de aprovechar éstas artísticamente. Análogamente, las técnicas de "organización total" del serialismo integral serían una espuria corrupción de la noción de "composición", porque con ellas el compositor se dispensa de toda intencionalidad con respecto a las decisiones creativas: se limita a aceptar los resultados y asumirlos según los produce el funcionamiento de un mecanismo, sin siquiera hacer intervenir su propia respuesta y juicio crítico personales sobre esos resultados. Cavell critica los excesos de registro notacional a que esto da lugar, cuyo caso extremo sería la música electrónica, que prescinde incluso de la mediación del intérprete, y a la cual Cavell acusa de inhumanidad. La opuesta tendencia "aleatoria" en las prácticas compositivas sería sólo un subterfugio, correlativo a los excesos de

71. MWM, pp. 194-196, 202-204, 207-209.

72. Cavell tampoco parece pensar que puedan legitimarse apelando a su concepto de "automatismo".

73. MWM, pp. 196, 203-204. 
control determinista de la música serial y electrónica, y pergeñado para compensar la sensación de pérdida de libertad $^{73}$.

De estas consideraciones de Cavell, se sigue que las obras representativas de la "nueva música" ya no dan forma musical al drama de la vida humana: han perdido la cualidad de tiempo direccional que da sentido a los eventos musicales, y su experiencia no es de presentness: no acontece en ella la franca donación de ningún significado. Dichas obras no expresan la voz del artista como individuo; pero tampoco se expresaría en ellas la voz de la comunidad, pues eso no es posible en una obra de la era modernista, donde pierden vigor las convenciones compartidas. Al no ser expresión de ninguna voz personal, ni individual ni colectiva, la obra musical se ve desprovista de todo significado. El compositor pierde con ello también a su audiencia, pero no ya porque su mensaje sea difícil de transmitir, sino porque no tiene nada que comunicar. Y sería esta incapacidad comunicativa lo que se destilaría en las revistas militantes de la Nueva Música, con su jerga técnica, su cientifismo y sus pretensiones revolucionarias, en un despliegue inauténtico de teatralidad que delata la caída de estos compositores y teóricos en el nihilismo escéptico más profundo.

\section{Sobre la vigencia de la crítica cavelliana de la "nueva música"}

¿Qué valor cabe otorgar, desde la perspectiva actual, al discurso de Cavell como comentarista y crítico de la música de su tiempo? Resulta algo embarazoso responder a esto. Es discutible, por ejemplo, la acusación cavelliana de una "carencia de objetivo" en las obras de música aleatoria: en tales obras hay unas instrucciones de ejecución, dadas por el compositor; el objetivo es aplicarlas para tocar una serie de materiales, también proporcionados por el compositor; y al menos en las obras más logradas de entre las realizadas con estas técnicas, se puede reconocer la identidad estética de la obra, su sonoridad, e incluso la identidad estilística del autor, como constantes a través de las diversas realizaciones o ejecuciones de la obra. Además, Cavell achaca la pérdida del componente intrínseco de espontaneidad musical a la escisión radical entre tendencias aleatorias y seriales. Pero, como ha señalado Franklin Cox, esta acusación deriva del modo artificioso e históricamente errado en que Cavell formula sus nociones de "azar", "improvisación" y "composición", malentendiendo la improvisación como si fuera un único tipo de práctica, no variable con el cambio de épocas, estilos, géneros o tradiciones musicales, y que presupusiera un marco igualmente invariable de convenciones compartidas colectivamente ${ }^{74}$. Esta misma falta de sentido histórico se podría echar en cara al entronizamiento cavelliano de la

74. Además de diversos tipos de improvisación en estilos históricos premodernos y en el Jazz, Cox señala los planteamientos recientes de compositores de la "Nueva Complejidad", como Brian Ferneyhough, ininteligibles desde una dicotomía entre determinismo compositivo y aleatoriedad (Cox, F., "Cavell on modern music", pp. 47-50). 
forma sonata clásico-romántica y de los recursos de la tonalidad funcional como paradigmas del medio musical.

Al menos en los textos aquí considerados, Cavell no muestra haber realizado un genuino esfuerzo por tomarse en serio las obras de los compositores que critica, y menos aún trata de articular discursivamente su propia "respuesta personal" a una experiencia real de escucha de ninguna de ellas en particular (contrariando así las exigencias que él mismo impone al crítico y al esteta modernistas). Se limita a hacer alusiones totalmente genéricas al Klavierstück XII de Karheinz Stockhausen, como pièce de scandale por su uso de ciertos procedimientos aleatorios, o al conjunto de las "obras tardías de Krenek" o de las de Cage, pero sin entrar en más detalles sobre dichas obras, relegándolas al estatuto de "imposturas" sin más consideraciones. Tampoco Cavell se compromete a dar una valoración positiva de obras de otros compositores "modernistas" que sean posteriores a la generación de un Schostakovich: en la vanguardia musical posterior a 1950, casi todo sería "inauténtico", pero Cavell se dispensa de indicarnos si entre todo ello no habría algunas obras o artistas "genuinos", y cuáles serían. Lo cual contrasta chocantemente con la atención y la valoración positiva que Cavell otorga a otros artistas contemporáneos del ámbito de las artes plásticas o la literatura, como el escultor Anthony Caro o el escritor Samuel Beckett ${ }^{75}$.

En vez de ello, Cavell alude repetidamente a lo que los compositores, o sus críticos y comentaristas, han dicho. Pero tampoco examina esos discursos de modo detallado, ni presta mucha atención al contenido de las revistas de la vanguardia musical que él mismo toma como testimonio sintomático al tiempo que denuesta: habla de ellas también en términos genéricos, sin reconocer las diferencias entre ellas, ni la pluralidad de autores y de posiciones teóricas que en ellas se expresaban ${ }^{76}$. En cambio, Cavell se limita a repetir un puñado de afirmaciones y clichés, comúnmente atribuidos a compositores y teóricos de la "nueva música", sobre el papel del compositor como artista y sobre la relación de sus obras con la ciencia y cultura contemporáneas y con la tradición del pasado; o a descripciones del proceso de producción de sus obras. Esta atención a los discursos sobre el arte es muy coherente con la concepción cavelliana de la tarea del esteta y del crítico, según la cual las declaraciones de los artistas son

75. Sobre Caro, cfr. MWM, pp. 216-217; al Endgame de Beckett le dedica Cavell un ensayo entero (MWM, pp. 115-162) Cox señala como única excepción los elogios de Cavell al compositor John Harbison (a quien hoy por hoy no suele considerarse, empero, entre los más importantes de su generación). Y añade como agravante la atención vertida por Cavell a los géneros más populares del cine clásico de Hollywood, cuyo estatuto como "alta cultura" es problemático, y que ciertamente no son "modernistas" (Cox, F., "Cavell on modern music", pp. 47,51 n. 26, 54). Sin embargo, Cavell y Fried arguyen que la naturaleza del medio cinematográfico (en cuyos detalles no podemos entrar) hace que la problemática del modernismo sea constitutivamente ajena a este arte.

76. De nuevo, coincidimos aquí con el análisis de Cox ("Cavell on modern music", pp. 52-53). 
un indicio tan válido como sus propias obras para conocer y juzgar su autenticidad y sus intenciones; sin embargo, no parece muy consistente con la suspicacia de Cavell hacia la figura del artista-teórico.

Seguramente la propuesta de cavelliana de "moralización" de la experiencia artística (tan antiformalista en su propósito como romántica o existencialista en su inspiración) será bien acogida por los partidarios del planteamiento eticista, que sostienen la relevancia de consideraciones éticas en el juicio y el discurso estéticos. Ahora bien, Cavell advierte que el precio de esta "moralización" sería una "desestetización" de dicha experiencia: una devaluación de su contenido sensorial y una condena un tanto inmoderada de sus efectos hedónicos ${ }^{77}$; la cual Ileva aparejada una sumisión de la acción creativa a su consideración instrumental como medio de expresión de un mensaje edificante (como denuncia Gordon C. F. Bearn ${ }^{78}$ ), y tal vez, cierto menosprecio del papel de los procesos técnicos en la creación, ya que lo importante es la "intención", el "mensaje"79. Hay que decir que la crítica de Bearn a Cavell es certera, aún sin necesidad de aceptar la posición hedonista de Bearn, que podría ser suscrita sin reparos por el ala más neoconservadora y antimodernista de los teóricos postmodernos. De hecho, si el discurso de Cavell sobre la "nueva música" ha logrado alguna aceptación actual, parece haber sido justamente entre los estetas, teóricos y críticos musicales más neoconservadores de la New Musicology. Éstos se hacen eco del énfasis casi exclusivo de Cavell en el aspecto más oscuro del arte moderno (la posibilidad de fraudulencia), con el fin de abjurar de cualquier "modernismo", al tiempo que justifican el "retorno a la tonalidad" como medio indispensable para satisfacer un presunto imperativo ético-artístico de inmediatez comunicativa, invocando el derecho de las grandes audiencias populares al gozo sencillo en la experiencia musical, al más puro modo romántico.

Sin embargo, es precisamente el romanticismo de Cavell, con su subjetivismo, su componente religioso y su ideal ético de sinceridad (plena concordancia de la intención con la acción) lo que arruina su planteamiento eticista. Pues Cavell en ningún momento define claramente los valores éticos que han de tenerse en cuenta (¿cuáles son esos valores?; ¿qué relación tienen con los valores estéticos?; etc.), ni está en condiciones de hacerlo. Ya que, al no poder contar más que con la sinceridad, la autenticidad, o a lo sumo, el ideal individualista del "perfeccionismo" emersoniano, Cavell ha de relegar esa cuestión al ámbito subjetivo-individual ${ }^{80}$, y su discurso eticista tiende a deslizarse hacia una espe-

77. Dos ejemplares de este tipo de discurso son: Tymoczo, D. "Dear Stanley"; y Kramer, L., "Music recomponed: Remarks in the history of the same", ambos en Cavell's 'Music discomposed', pp. 5-24 y 25-36, respectivamente).

78. Bearn, G., "Staging authenticity", p. 307. Bearn también señala que el proyecto de Cavell es él mismo "teatral".

79. Cfr. MWM, p. 228 n. 6, sobre la devaluación de lo sensorial.

80. Así lo señala, muy agudamente, Cox ("Cavell on modern music", p. 43). 
cie de "retórica de la autenticidad". Del mismo modo, las objeciones de Cavell contra la "nueva música" parecen una coartada retórica y dogmática para sus propios prejuicios, pues finalmente depende de unas "respuestas" o intuiciones personales suyas, siempre muy discutibles, que no necesariamente proceden de experiencias reales de las obras musicales vanguardistas a las que se refieren (y sin que Cavell pueda negar que hayan quienes experimenten ante esa misma música intuiciones opuestas, ni pueda tampoco argumentar o dialogar, con éstos: finalmente, es todo una cuestión de fe, de "revelaciones" incompatibles). Creemos, pues, que Cavell no logra plantear un pensamiento estético eticista viable. Y ello, por más que sintonice con la insistencia, tan característica de nuestra época actual, en afirmar la importancia de los valores en cualquier esfera de la actividad humana (que no siempre se ve acompañada de un esfuerzo serio por pensar esos valores). Este rasgo de nuestra época es también un síntoma de sus carencias; pues suele suceder que aquello que con más ahínco se afirma y pretende, es justamente lo que no se tiene. 